\title{
Experimental study of horizontal effects of flow on non-erosion absorbers in the presence of cavitation
}

\author{
Bakhtiyor Obidov, Oybek Vokhidov ", Javlon Suyunov, Khayrulla Nishanbaev, \\ Iroda Rayimova, and Abomuslim Abdukhalilov \\ Tashkent Institute of Irrigation and Agricultural Mechanization Engineers, Tashkent, Uzbekistan
}

\begin{abstract}
This article is devoted to one relatively small issue of the dynamics of hydraulic structures, the determination of horizontal hydrodynamic loads on energy absorbers of a high-pressure catchment area in a cavitating flow in the presence of erosion-free absorbers. In connection with the intensive construction of high and medium-pressure hydroelectric systems, spillways that operate at high flow rates, a very urgent task is to develop reliable and economical downstream devices that provide intensive damping of flow energy in a stilling well with favorable uninterrupted flow regimes and the absence of cavitation erosion of streamlined elements.

Traditional methods of extinguishing energy using stilling wells and walls do not always solve the problem. In several cases, additional elements such as energy absorbers are installed, which effectively deal with malfunctioning currents. However, most of the used types of absorbers have a serious drawback - they are destroyed during cavitation studies by prof. N.P. Rozanov and his students made it possible, based on experiments, to develop several types of erosion-free or close to erosionfree dampers and obtain a dependence to determine the hydrodynamic loads acting on them at various stages of cavitation. This made it possible to use energy absorbers at high flow rates, which was done at the spillways of the Shamkhor and Artyomovsk hydroelectric power plants.
\end{abstract}

\section{Introduction}

\subsection{Force effects of the flow on the elements of hydraulic structures in the presence of cavitation}

The question of the influence of cavitation on the pulsation characteristics of the flow, as far as we know, has practically not been studied. However, a qualitative understanding of pressure pulsations on absorbers can be obtained by the example of studies studying the pulsation characteristics with various kinds of obstacles (protrusions, gates, etc.) since both are essential sources of cavitation, turbulence and pressure pulsations.

"Corresponding author: vohidov.oybek@bk.ru 
In (1), the data of laboratory tests of a flat gate operating in a high-speed flow at heads up to $200 \mathrm{~m}$ were carried out. One of the aspects of the work was studying the dynamic effect of the cavitating flow on the valve. According to the authors, the values of the pressure pulsation standards at the gate in the presence of developed cavitation are twice the values of the standards in the absence of cavitation. In the supercavitation mode, such data are not presented because the authors of the work failed to obtain supercavitation.

The works of V.M. Lyatkher and L.V. Smirnov [1-5] obtained data on the characteristics of pressure pulsation in the flow separation zone at different absolute pressures. There is an increase in the dispersion and the existing deformation of the pulsation spectrum towards high frequencies as cavitation develops. In the separation zone, the change in the spectrum during cavitation is natural because the most intense pulsations occur in the presence of cavitation. A. Lokher and E. Naudalper [6-13], carrying out systematic studies, obtained the intensity of pressure pulsation on the protruding walls, depending on the number of cavitation to obtain information about the vibrations of structures caused by the flow. In frequent cases of pulsation, the pressure was measured on the protruding wall. It was found that the intensity of pressure fluctuations, linear correlation and spectra of wall pressure fluctuations strongly depend on the adhesion of the streamlined flow to the wall. In the beginning, the case of the absence of cavitation and without adhesion was investigated $(d / b=1.0)$. At, $d / b=1.0$ the main frequency was not found in the spectrum of pressure pulsations, and the intensity of this load was relatively low $\left(0.078 \mathrm{\rho u}_{\mathrm{o}}^{2} / 2\right)$.

In the case of unstable adhesion of the flow to the wall (for $d / b=3.0$ ), the force effects of the flow are distinguished by a high-frequency spectrum and pronounced peaks, while the rms pressure pulsations are much higher $\left(0.13 \mathrm{\rho u}_{0}^{2} / 2\right)$. Cavitations at different stages lead to increased flow pulsations, thereby leading to more intense pressure pulsations in the low-frequency part of the spectrum, not only in cases where the flow does not adhere to the streamlined wall.

For a flow with unstable adhesion, cavitation works with it in antiphase, which leads to a decrease in the relative intensity of low-frequency oscillations.

High-frequency oscillations, as the spectra of pressure pulsations show, increase in both cases due to the ultrasonic spectrum of the cavitation phenomenon itself. With supercavitation $\mathrm{K}=1.8$, the pulsation standard decreases significantly. The authors of the reports explain the discovered phenomenon by the damping effect of air bubbles released from the water in the low-pressure zone and accumulating in the displacement zone. Apparently, the cavitation steam-gas cavities themselves have a similar effect. S. Wiegander and U. Chi $[9,10]$ observed the transformation of the exposure spectrum in the region of reattachment of the flow and found a 6 -fold increase in pressure fluctuation.

For the first time in hydraulic engineering, the force effects of a cavitation-other flow on erosion-free dampers were studied by N.N. Rozanova [20, 21]. Based on cavitation studies, the author of this work obtained quantitative regularities of horizontal averaged pulsation loads on absorbers as cavitation develops. During the experiments, a decrease in drag coefficients with the development of cavitation was recorded. The resulting graphical dependence $C_{\text {cav }} / C_{0}=f(\beta)$ for a jump in the limiting state indicates a change in the drag coefficient of erosion-free absorbers and is approximated by the dependence $C_{\text {cav }} / C_{0}=$ $\beta^{0.6}$.

The author of the work explains that it changes with the development of cavitation. A decrease in the coefficient of resistance during cavitation, especially in conditions and supercavitation, is noted.

The nature of the pressure distribution diagrams on the streamlined body at the second stage, the author studies the pulsation loads on the absorbers along the maximum swing. 
The analysis of the research results showed that when the absorbers work under cavitation conditions (initial and developed), there is an increase in the instantaneous pulsating component of the load compared to the cavitation-free mode. For example, in the cavitation-free mode, the ripple coefficient $\delta_{n}$ is constant and equal to 0.14 . And at the developed stage $(\beta=0,5) \delta_{n}=0,65$ T.e increased by 4.6 times, and at $(\beta<0,5)$ there is a tendency to its decrease.

According to the review, the writers show that the working conditions of the downstream extinguishing devices of high-pressure structures are very difficult.

At flow velocities over $12-15 \mathrm{~m} / \mathrm{s}$, downstream damping devices, as a rule, operate in a cavitation mode.

First of all, this mode of operation gives rise to erosional destruction of the damper itself and the slabs located near it. This occurs where the cavitation torch closes on the structure.

\section{Methods}

\subsection{Experimental technique. Vacuum unit, models and similarity criteria}

To reproduce cavitation and study its effect on the elements of hydraulic structures, various cavitation installations are used.

To obtain data on the conditions for the emergence, development and impact of a cavitating flow on the elements of spillway structures, vacuum stands are used. Their main advantage lies in the fact that they allow to creation cavitation conditions on models that meet the criteria of similarity of a Frud number.

The working chamber of the cavitation stand must be of sufficient size to accommodate large models and must provide for the reproduction of sections of structures with a free water surface.

In the working chamber of these trays, a reduced pressure must be maintained following the scale of the models. Despite the low speeds in the working chamber, the pumping equipment of the vacuum stand must be designed for relatively high costs. In Russia, vacuum cavitation stands for testing hydraulic structures was first implemented at the suggestion of N.P. Rozanov [21] at NIS Gidroproekt in 1960. The stand is equipped with vacuum pumps that allow reaching a vacuum of up to $9.8 \mathrm{~m}$. The water consumption in the model can reach 500 1/s. Such installations are currently successfully used at VNIIGE im. B.E. Vedeneev, NIS Gidroproekt and MGMI. At these stands, cavitation studies of watersupply structures of the Sayano-Shushensky, Atbashinsky, Shamkhorsky, Bortogaysky, Nizhne-Kafirnigansky and other high-pressure hydrosystem operating in cavitation conditions were carried out.

The research was carried out at the vacuum bench of the laboratory of hydraulic structures of the MGMI. [18-32].

It is known that when simulating the operation of energy absorbers in downstream during cavitation, it is necessary to observe the Froude similarity criterion $(\mathrm{Fr}=\mathrm{idem})$ and to carry out studies in the self-similar region at Reynolds numbers $R e_{m}>R e_{g r}$.

The experiments were carried out at Froude numbers calculated for a compressed section $\mathrm{Fr}_{1}=16-64$ and Reynolds numberRe $e_{1}=4 * 10^{5}-1.1 * 10^{6}$.

To observe the approximate similarity of cavitation phenomena, it is necessary to fulfill the conditions:

$$
K_{n}=\eta K_{m}
$$


where: $K_{n}$ and $K_{m}$ are parameters of cavitation for nature and model; $\eta$ is model scale correction factor (was accepted $\eta-1.0$ given the large scale of the model $R e_{m}>10^{5}-$ $10^{6}$.

The absence of cavitation will be ensured provided

$$
K>K_{c r}
$$

The cavitation parameter is usually written as follows:

$$
K=\frac{H_{h a r}-H_{c r}}{v_{\text {har }}^{2} / 2 g}
$$

where: $H_{h a r}=H_{a}+h\left(H_{a}\right.$ is pressure created above a free surface in a cavitation unit, m.w.c., for nature - atmospheric pressure); $h$ is height of the water column under the damper m.w.c.; $v_{\text {har }}$ is characteristic flow velocity (taken from the velocity distribution diagram at the level of the damper top), $\mathrm{m} / \mathrm{s} ; g$ is free fall acceleration, $\mathrm{m} / \mathrm{s}^{2} ; H_{c r}$ is pressure (m.w.c.) vaporization (taken as for pure water).

In experiments, cavitation in its various stages was created by adjusting the vacuum.

A hydraulic jump in the installation was created when water was flowing out from under a shutter with a sharp edge.

The fragmentary model was a pond with two rows of damping devices: in the first row, erosion-free dampers, in the second, a pond.

We have investigated four types without erosion absorbers (Figure 1).

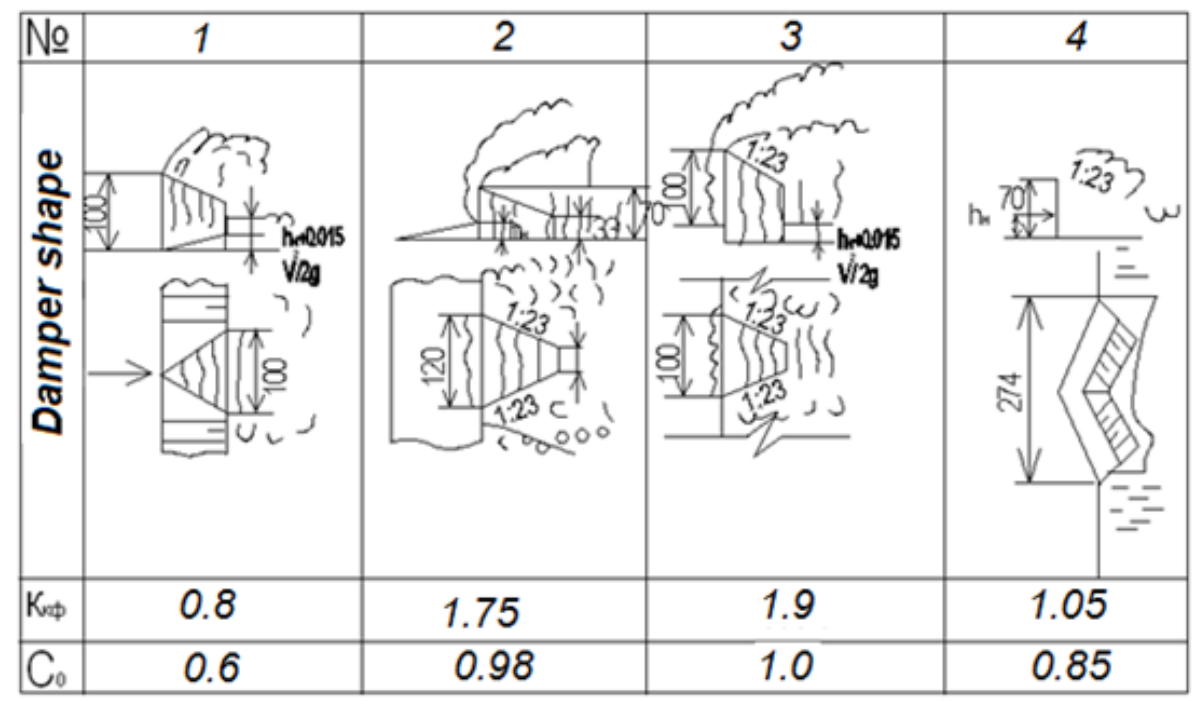

Fig. 1. Study of the shape of model erosion-free energy absorbers (dimensions in $\mathrm{mm}$ )

The research used the following device: plate sensor - to measure the averaged and variable component of the horizontal load acting on the damper. 


\section{Results and Discussion}

\subsection{Results of cavitation studies}

It is obvious that, in addition to vertical hydrodynamic loads, those slabs of the water face are also subject to horizontal loads due to both static and dynamic components of the flow. In this regard, research on identifying the contribution of the dynamic component to the total horizontal load in cavitation and cavitation-free modes is of certain interest.

In non-cavitation modes, this issue was studied in [14-16], where it was noted that the contribution of the dynamic component to the total horizontal loads is very significant, amounting to $25-30 \%$. Studies of the static component (resistance coefficient) of the horizontal load for three types of absorbers (№ 1, 2, 3), as well as the pulsation load for the damper № 2 are given in [1-4].

The purpose of our research was to study the influence of the cavitation stage on additional changes in the pulsation component for four types of absorbers.

Along the way, we determined the drag coefficients for the indicated types of absorbers and gave a comparative graph of their dependence on the stage of cavitation (Figs. 2 and 3). It can be seen from the figure that the results of our studies practically coincide with those given in [7-15].

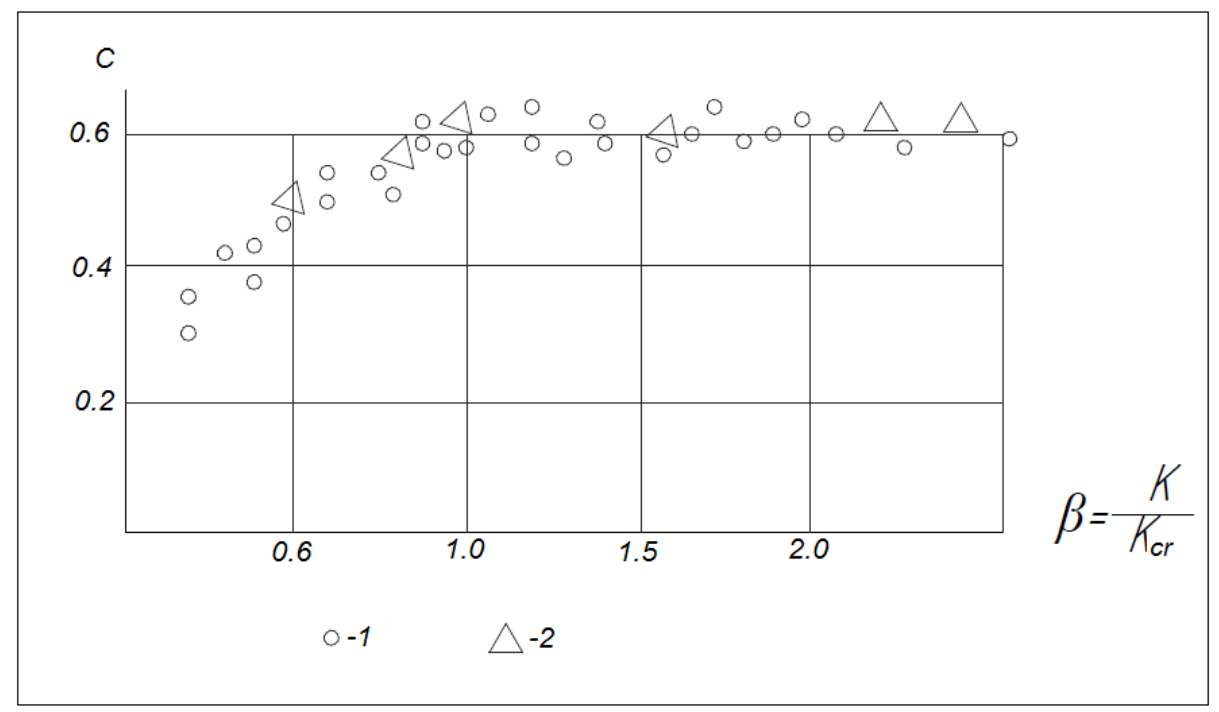

Fig. 2. Change in the drag coefficient of absorber No. 1 depending on the stage of cavitation ( $\beta$ ): 1 is author's data; 2 is data N.N. Rozanova [20] 


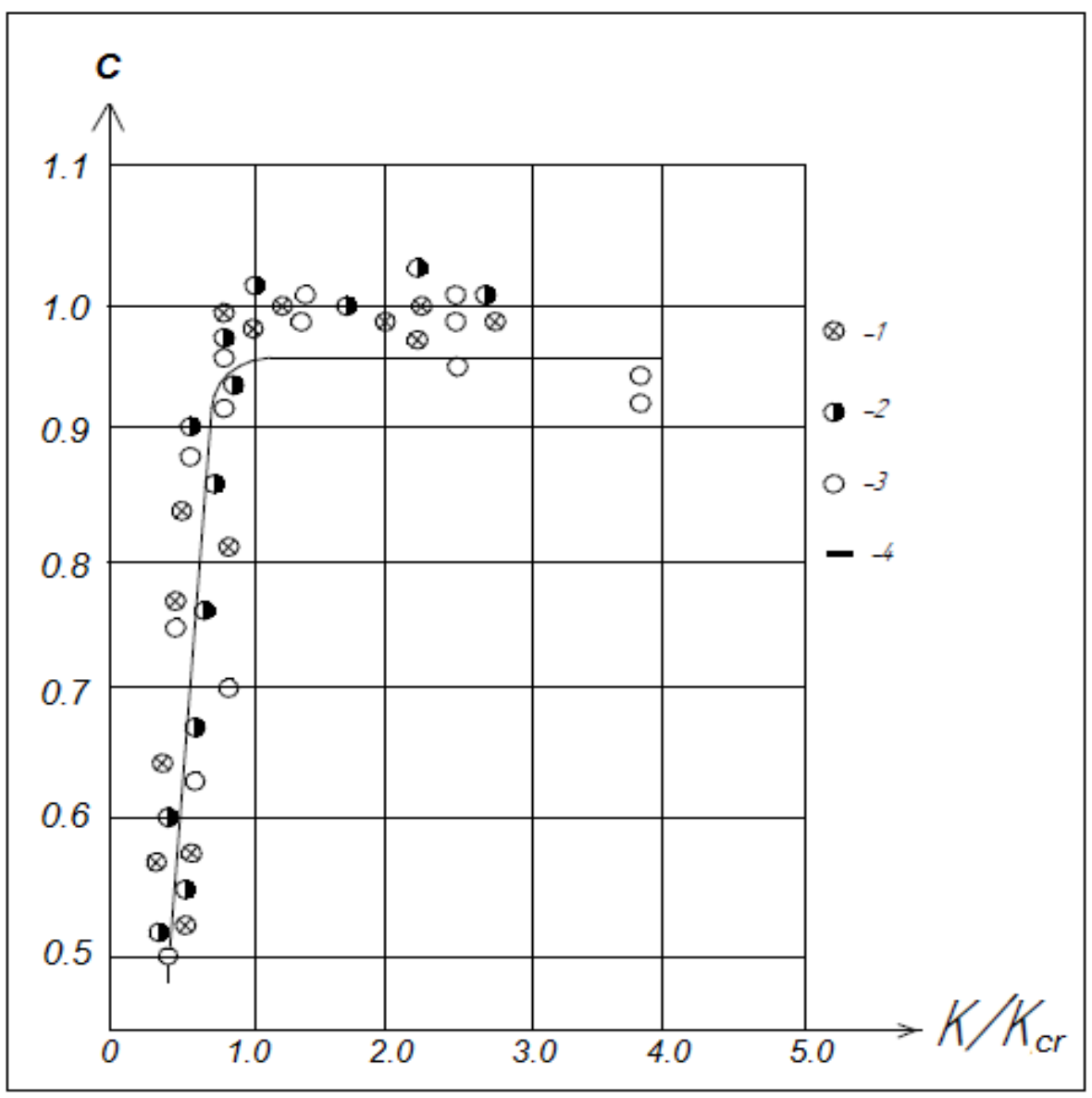

Fig. 3. Change in the resistance coefficient of the damper № 2 and 3 depending on the stage of cavitation: 1 is for the damper № 2; 2 is for the damper № 3; 3 and 4 are data [21] for the damper № 2 .

Also, the dependence of the drag coefficient on the stage of cavitation for the newly studied erosion-free damper of the diffuser was found out (Figure 4). 


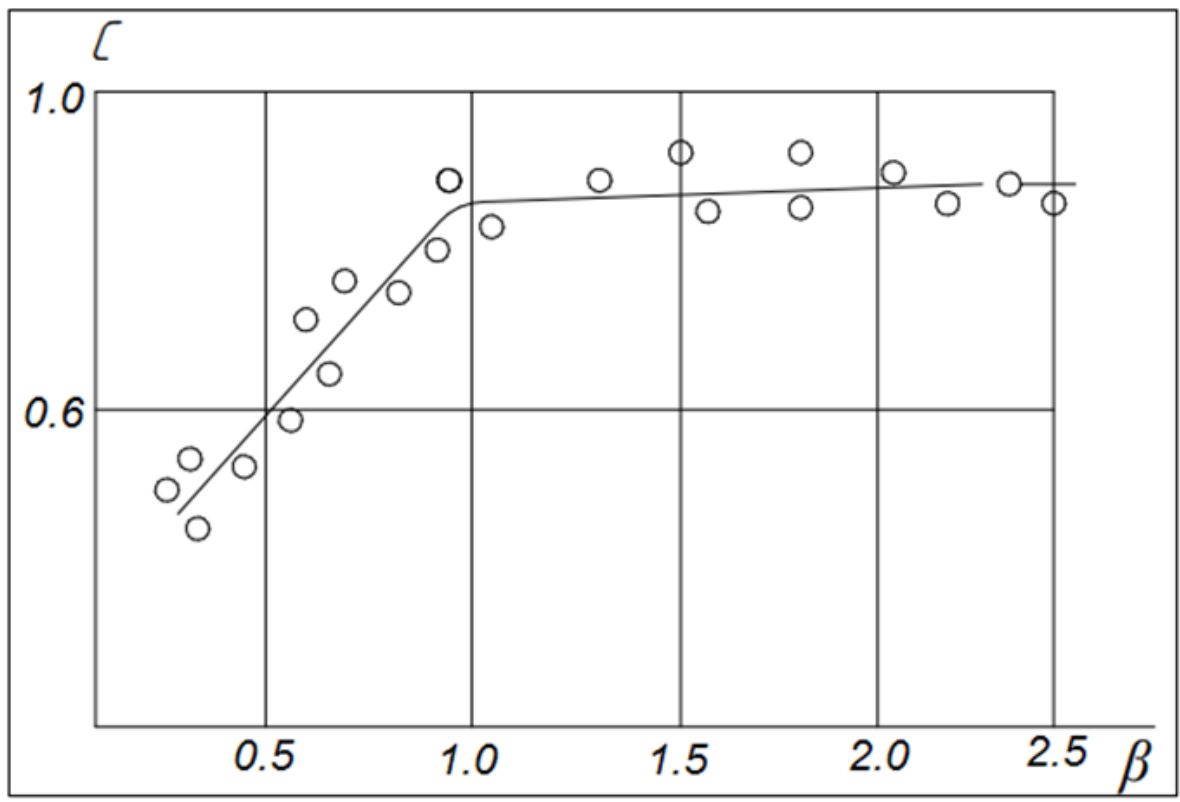

Fig. 4. Coefficient of resistance of the absorber-diffuser depending on the stage of cavitation [20]

It should be noted that the nature of the change in the drag coefficient for the specified diffuser damper is similar to the change in the drag coefficients for the remaining absorbers, and in the cavitation-free mode, its value was 0.85 .

For all investigated types of absorbers, a decrease in the drag coefficients $(C)$ with the development of the cavitation stage was observed. Based on the average pressure measurements on the dampers using the plate sensor, their resistance coefficients were determined in the form of functions $\frac{C_{c a v}}{C_{0}}=f(\beta)$. The decrease in $C$ can be explained by the fact that, with the development of cavitation, the character of the pressure distribution curves on the streamlined body changes. At the initial stage of cavitation, the closeness of the values of $C_{0}$ and $C_{c a v}$, should be expected, which was obtained in the experiments, since the limiting vacuum on the rear surface of the energy absorber does not appear at all points of the vacuum zone.

Noticeable decrease $C_{c a v}$ occurs during the developed stage and supercavitation. Obviously, the explanation for the decrease in $\mathrm{C}$ during cavitation is quite consistent with the physics of the phenomenon, and the data are given in the work [14]. Thus, with the development of cavitation, there is a slight decrease in the energy-absorbing capacity of the absorbers, which, of course, must be taken into account the head. Despite the decrease in $C$, an important function will remain - to combat its course and the formation of a favorable flow regime.

The static processing of the pulsating component of the horizontal hydrodynamic load standards for all the studied absorbers showed that its value in the cavitation-free mode is $20-25 \%$ of the static component of the hydrodynamic load, depending on the type of absorbers.

Figure 5 shows the horizontal load ripple standards $\left(P_{g}^{\prime}\right)$ as a fraction of the horizontal load $\left(\bar{P}_{g}\right)$ for investigated absorbers. As you can see, as cavitation develops, the value $\left(P_{g}^{\prime} / \bar{P}_{g}\right)$ first increases significantly and then sharply decreases. The highest value $\left(P_{g}^{\prime} / \bar{P}_{g}\right)$ corresponds to the advanced stages of cavitation $(\beta=0.5)$. It is noted that with an increase in the absorber's resistance coefficient, the contribution of the horizontal pulsation load also 
increases. This can be explained, apparently, because the lower the resistance coefficients of the absorber, the more streamlined it is and, therefore, creates fewer turbulent eddies directly associated with pulsation loads.

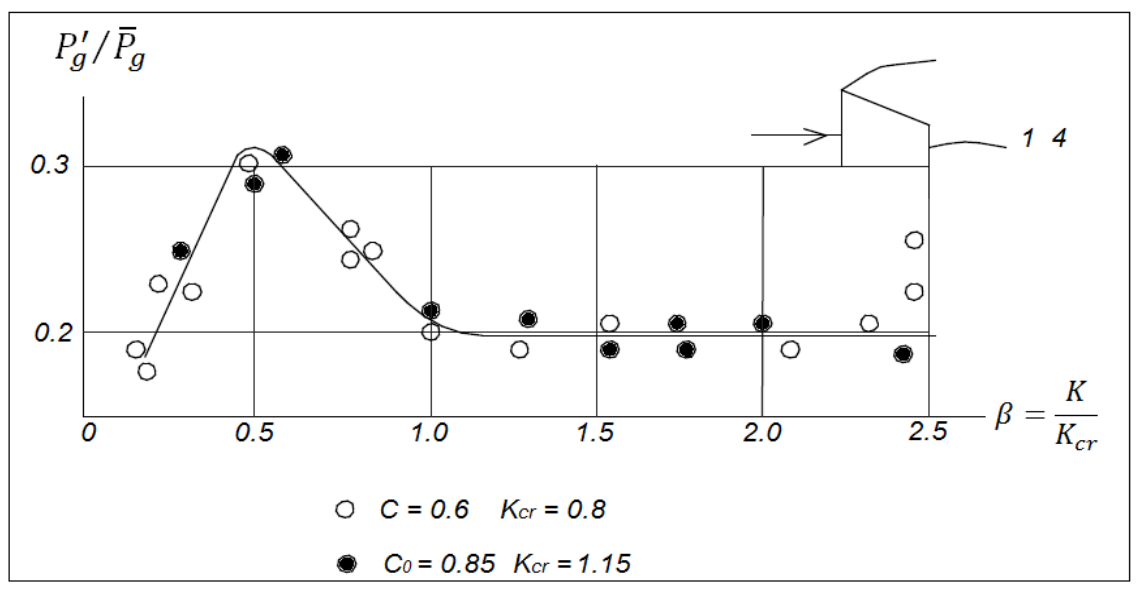

a)

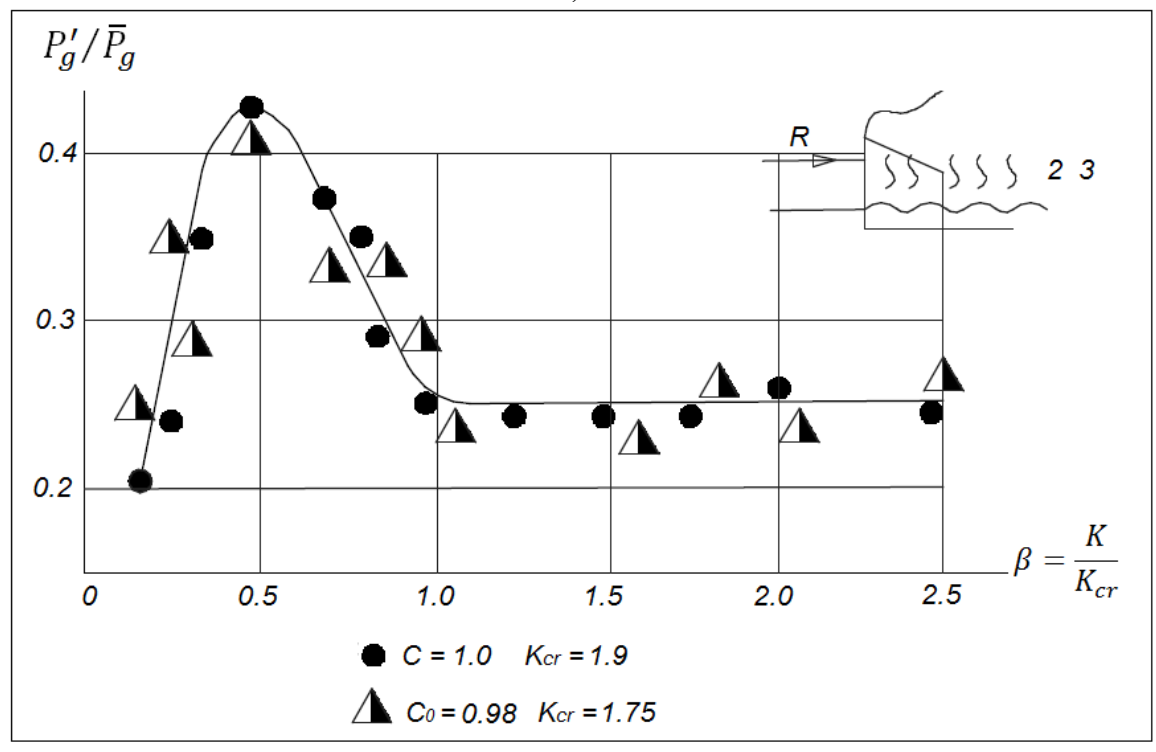

b)

Fig. 5. Dependence of the horizontal pulsation load on the stage of cavitation: a is for absorbers № 1, 4 ; $\mathrm{b}$ is for absorbers № 2 and 3

Studies of the horizontal pulsating load in the cavitation mode for different types of absorbers have shown that the presence of cavitation further increases the horizontal total pulsating loads.

In conclusion, it should be noted that an increase in the pulsating horizontal loads on the slabs of the reservoir due to cavitation, as well as a decrease in their energy-absorbing properties, will undoubtedly make adjustments to the calculations of the shear stability of the slabs, as well as the strength of the absorbers themselves. 


\section{Conclusions}

1. The present studies show that the drag coefficients of the investigated non-erosion energy absorbers significantly decrease with the development of cavitation. Changes in the resistance coefficients should be considered in the calculations for the required energy absorption capacity.

2. Studies of the horizontal pulsating load in the cavitation mode of the investigated absorbers showed that the presence of cavitation further increases the horizontal pulsating loads. For the investigated types of absorbers, the ripple load is 1.7 times concerning the ripple load without cavitation.

3. In the developed stage of cavitation $(\beta=0.5)$, the main energy-absorbing frequencies of horizontal hydrodynamic loads are mixed towards high frequencies. load.

4. Research has shown that the horizontal ripple load is equal to a quarter of the static

5. Specific horizontal load is largely determined by the stage of cavitation.

\section{References}

1. Obidov B., Vokhidov O., Tadjieva D., Kurbanova, U., Isakov A. Hydrodynamic effects on the flow elements of the downstream devices in the presence of cavitation. IOP Conf. Ser. Mater. Sci. Eng. 1030, 012114 (2021).

2. Bazarov D., Vatin N., Obidov B., and Vokhidov O. Hydrodynamic effects of the flow on the slab of the stand in the presence of cavitation. IOP Conf. Ser. Mater. Sci. Eng. 1030, 012110 (2021).

3. Bazarov D. and Vokhidov O. Extinguishing Excess Flow Energy in Spillway Structures. In book: Proceedings of EECE 2020, LNCE 150, pp. 535-545, (2021) DOI: 10.1007/978-3-030-72404-7_52

4. Bazarov D., Norkulov B., Vokhidov O., Uljaev F., Ishankulov, Z. Two-dimensional flow movement in the area of protective regulatory structures. IOP Conf. Ser. Mater. Sci. Eng. 890, 012162 (2020)

5. Chernykh O.N. Hydrodynamic loads and stability of the downstream fastening of hydraulic structures. Power Technol. Eng. 24., (1983)

6. Tsvetkov P.K. To the calculation of a hydraulic jump in an expanding channel Proc. Inst. Hydrol., pp. 79-93, (1952)

7. Krutov A., Norkulov B., Uljaev F., and Jamalov F. Results of a numerical study of currents in the vicinity of a damless water intake. IOP Conf. Ser. Mater. Sci. Eng. 1030, 012121 (2021).

8. Krutov A., Norkulov B., Mavlyanova D. Simulation of spreading of non-conservative passive substances in water bodies. IOP Conf. Ser. Mater. Sci. Eng. 883(1), 012028 (2020)

9. Krutov A., Choriev R., Norkulov B., Mavlyanova D. and Shomurodov A. Mathematical modelling of bottom deformations in the kinematic wave approximation. IOP Conf. Ser. Mater. Sci. Eng. 1030, 012147 (2021).

10. Bazarov D., Markova I., Sultanov S. and Kattakulov F. Dynamics of the hydraulic and alluvial regime of the lower reaches of the Amudarya after the commissioning of the Takhiatash and Tuyamuyun hydrosystems. IOP Conf. Ser. Mater. Sci. Eng. 1030, 012110 (2021).

11. Ivanov V.M. Improving the theory and methods of calculation hydrodynamic effects on spillway structures. (2004)

12. Wilson E.H. Boundary layer effects on hydraulic jump location Hydraul. Div. pp.1126-1136, (1972) 
13. Arndt R.E.A. Cavitation in fluid machinery and hydraulic structures. Annu. Rev. Fluid Mech. 13. pp. 274-328. (1981)

14. Altimira M., Fuchs L. Numerical investigation of throttle flow under cavitating conditions, International Journal of Multiphase Flow. 75, pp. 124-136, (2015)

15. Amromin E. Determination of Cavity Detachment for Sheet Cavitation, Journal of Fluids Engineering, 129, pp. 1105-1111, (2007)

16. Amromin E., Kopriva J., Arndt R.E.A., Wosnik M. Hydrofoil Drag Reduction by Partial Cavitation // Journal of Fluids Engineering. 128, pp. 931-936, (2006)

17. Rybakov V., Jos V., Raimova I., and Kudryavtsev K. Modal analysis of frameless arches made of thin-walled steel profiles. IOP Conf. Ser. Mater. Sci. Eng. 883, (2020).

18. Bazarov D., Markova I., Raimova I., Sultanov Sh. Water flow motion in the vehicle of main channels. IOP Conf. Ser. Mater. Sci. Eng. 883, 012025 (2020).

19. Uralov B., Rakhmatov N., Khidirov S., Uljaev F., Raimova I. Hydraulic modes of damless water intake. IOP Conf. Ser. Mater. Sci. Eng. 1030(1), 012123 (2021)

20. Rozanova N.N. Issledovaniye gasheniya energii v vysokonapornykh vodosbrosakh v usloviyakh propuska zakruchennykh potokov i pri kavitatsii. (1979).

21. Obidov B.M. Gidrodinamicheskiye vozdeystviya potoka na elementy ustroystv nizhnego b'yefa pri nalichii kavitatsii na bezerozionnykh gasitelyakh. (1985).

22. Obidov B., Choriev R., Vokhidov O. and Rajabov M. Experimental studies of horizontal flow effects in the presence of cavitation on erosion - free dampers. IOP Conf. Ser. Mater. Sci. Eng. 883, 012051 (2020).

23. Obidov B., Vokhidov O., Shodiev B., Ashirov B. and Sapaeva M. Hydrodynamic loads on a water drain with cavitation quenchers. IOP Conf. Ser. Mater. Sci. Eng. 883, 012011 (2020).

24. Krutov A., Norkulov B., Artikbekova F., Nurmatov P. Optimal location of an intake at a reservoir prone to salt diffusion. IOP Conf. Ser. Mater. Sci. Eng. 869(7), 072020, (2020)

25. Eshev S., Latipov S., Qurbonov A., Berdiev M., Mamatov N. Non-eroding speed of water flow of channels running in cohesive soils. IOP Conf. Ser. Mater. Sci. Eng. 1030, 012131 (2021).

26. Eshev S., Rakhimov A., Gayimnazarov I., Shodiev B., Bobomurodov F. Dynamically stable sections of large soil canals taking into account wind waves. IOP Conf. Ser. Mater. Sci. Eng. 1030, 012134 (2021).

27. Gur'ev,A.P., Kozlov D.V., Khanov N.V., Abidov M.M., Safonova N.A. Alternative Solutions for the Energy Dissipation of Idle Discharges at the Rogun HPP, Power Technology and Engineering, 54(1), pp. 7-12, (2020)

28. Baranov E.V., Gur'yev A.P., Khanov N.V. Recommendations for Hydraulic Calculations of Anti-Erosion Lining with the Use of Spatial Geogrid with Coarse Fragmental Soil, Power Technology and Engineering, 53(5), pp. 553-556, (2020)

29. Khanov N.V., Martynov D.Y., Novichenko A.I., Lagutina N.V., Rodionova S.M. Outlook and Special Properties of Earth Anchors and Screw Piles in Burial of Modular Protection Dikes in Nonrocky Ground, Power Technology and Engineering, 52(4), pp. 405-412, (2018)

30. Kurbanov S.O., Khanov N.V. To calculation of the critical depths of the canals with polygonal profile (PP), Gidrotekhnicheskoe Stroitel'stvo, (3), pp. 42-44, (2004)

31. Kurbanov S.O., Khanov N.V. To hydraulic calculation of the most favorable sections of the power diversion canals (PDC) of a polygonal profile, Gidrotekhnicheskoe Stroitel'stvo, (7), pp. 40-43, (2003)

32. Khanov N.V. Hydraulic characteristics of chamber-free tangential vortex flow generators, Hydrotechnical Construction, 33(2), pp. 99-103, (1999) 
